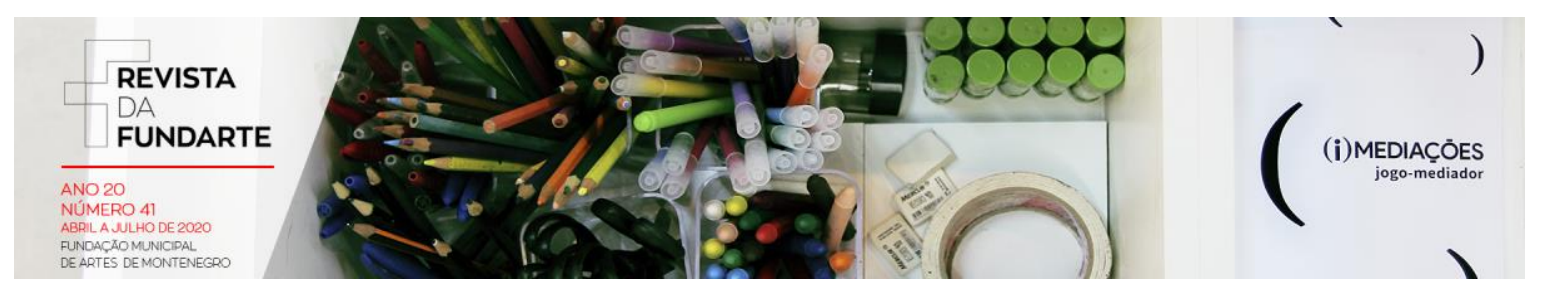

\title{
PRODUÇÃO DE CONHECIMENTO SOBRE DANÇAS DE SALÃO: UM LEVANTAMENTO DE LIVROS, TESES E DISSERTAÇÕES NO BRASIL
}

\author{
Bruno Blois Nunes \\ Flávia Marchi Nascimento
}

DOI: http://dx.doi.org/10.19179/2F2319-0868.701

NUNES, Bruno Blois; NASCIMENTO, Flávia Marchi. Produção de conhecimento sobre danças de salão: um levantamento de Livros, Teses e Dissertações no Brasil. Revista da FUNDARTE. Montenegro, p.0120, ano 20, no 41, Abril/Junho de 2020.

Disponível em: http://.seer.fundarte.rs.gov.br/index.php/RevistadaFundarte/index> 30 de junho de 2020. 


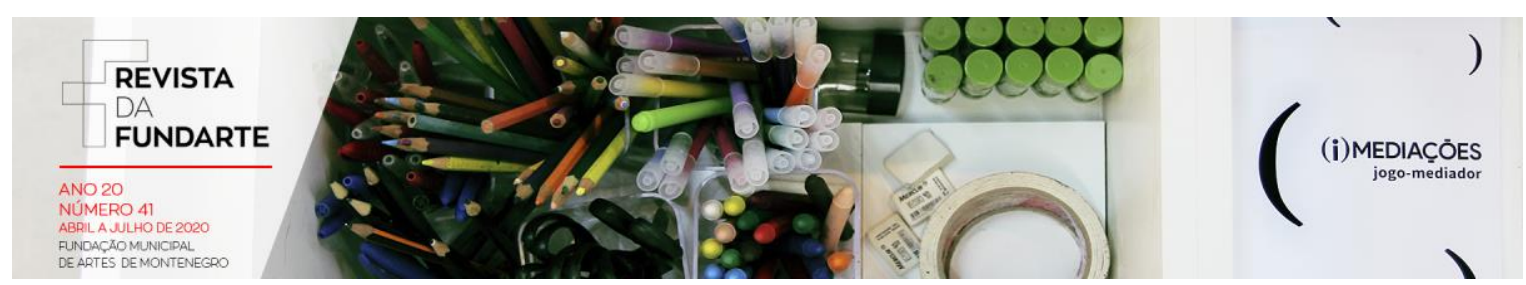

\title{
PRODUÇÃO DE CONHECIMENTO SOBRE DANÇAS DE SALÃO: UM LEVANTAMENTO DE LIVROS, TESES E DISSERTAÇÕES NO BRASIL
}

\author{
Bruno Blois Nunes ${ }^{1}$ \\ Flávia Marchi Nascimento²
}

Resumo: Este artigo é fruto de projeto de pesquisa desenvolvido no Curso de Dança da Universidade Federal de Pelotas (UFPel). O objetivo desse trabalho é fazer um levantamento das produções de livros, dissertações e teses sobre dança de salão viabilizando a observação de possíveis lacunas e carências em relação a produção acadêmica no intuito de fomentar a ampliação da discussão na área. Foi utilizada a palavra-chave "dança de salão" em duas plataformas de consulta online: Catálogo de Teses e Dissertações - CAPES e Fundação Biblioteca Nacional. Os resultados revelaram que há uma notória escassez teórica de pesquisas voltadas à dança de salão o que revela a necessidade de mais estudos na área como forma de fortalecê-lo no âmbito acadêmico.

Palavras-chave: Dança; Dança de salão; Produção acadêmica.

\section{PRODUCTION OF KNOWLEDGE ABOUT BALLROOM DANCES: A SURVEY OF BOOKS, THESES AND DISSERTATIONS IN BRAZIL}

\begin{abstract}
This article is the result of a research project developed at the Dance Course of Federal University of Pelotas (UFPel). The objective of this work is to make a survey of the productions of books, dissertations and thesis on ballroom dancing, enabling the observation of possible gaps and deficiencies in relation to the academic production in order to foster broader discussion in the area. The keyword "ballroom dancing" in two online search engines: Catalog of Theses and Dissertations - CAPES and National Library Foundation. The results revealed that there is a notorious theoretical shortage of research focused on ballroom dancing which reveals the necessity for further studies in the area as a way to strengthen it in the academic field.
\end{abstract}

1 Doutorando em Educação (UFPel/RS)

Mestre em História (UFPel/RS)

Especialista em Linguaguens Verbo-Visuais e suas Tecnologias (IFSul-Pelotas/RS)

Graduado em Educação Física (UFPel/RS) e Graduando em Dança (UFPel/RS)

2 Professora do Curso de Dança - Licenciatura (UFPel)

Doutoranda em Educação (UFPel/RS)

Mestre em Educação Física (UFPel/RS)

Especialista em Pesquisa em Educação Física (UFPel/RS)

Graduada em Educação Física (UFPel/RS)

NUNES, Bruno Blois; NASCIMENTO, Flávia Marchi. Produção de conhecimento sobre danças de salão: um levantamento de Livros, Teses e Dissertações no Brasil. Revista da FUNDARTE. Montenegro, p.0120, ano 20, no 41, Abril/Junho de 2020.

Disponível em: http://.seer.fundarte.rs.gov.br/index.php/RevistadaFundarte/index> 30 de junho de 2020. 


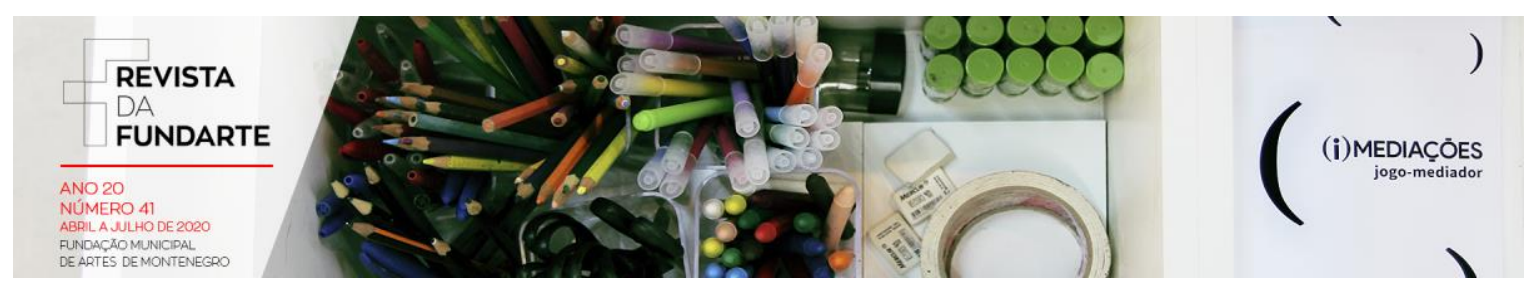

Keywords: Dance; Ballroom dancing; Academic production.

\section{Introdução}

A dança acompanha o homem desde os primórdios e vários autores mencionam suas raízes pré-históricas (NUNES, 2016, p. 65). Portinari menciona que "o homem primitivo dançava com vitalidade física utilizando a dança como ferramenta rudimentar de comunicação e, futuramente, ser utilizada dentro dos rituais (1989, p. 17). Inúmeras danças poderiam ser encontradas nesses grupos primitivos:

\footnotetext{
Desde as priscas eras da humanidade a dança esteve presente. Há entre os povos pré-letrados uma série de danças como as de caça, de máscaras, guerreiras e secretas, as nupciais, as de fecundidade ou eróticas ou genéticas, as de nascimento, de iniciação ou circuncisionais, as fúnebres, as medicinais, as de colheita, as lunares, as plêiades, as festivas ou puramente recreativas, as mágicas, as religiosas ou sagradas ou propiciatórias, as imitatórias, as lúdicas etc. (ARAÚJO, 2004, p. 5).
}

Embora a dança esteja presente desde os primórdios da humanidade, sua aparição, especialmente no meio acadêmico, ainda é muito tímida. Isso pode ser reflexo da escassa formação em dança em nossas universidades brasileiras. Apesar da implementação do primeiro curso superior de dança no Brasil ocorrer em 1956, na Universidade Federal da Bahia (UFBA), somente a partir da segunda metade da década de 1990 é possível perceber o ensino da dança consolidando-se nas universidades espalhadas pelo Brasil (CORRÊA; NASCIMENTO, 2013, p. 57).

Tendo em vista a recente consolidação da área da dança no ambiente acadêmico, esse estudo tem como objetivo fazer um estado da arte para compreender o que tem sido produzido além de viabilizar a observação de

NUNES, Bruno Blois; NASCIMENTO, Flávia Marchi. Produção de conhecimento sobre danças de salão: um levantamento de Livros, Teses e Dissertações no Brasil. Revista da FUNDARTE. Montenegro, p.0120, ano 20, no 41, Abril/Junho de 2020.

Disponível em: http://.seer.fundarte.rs.gov.br/index.php/RevistadaFundarte/index> 30 de junho de 2020. 


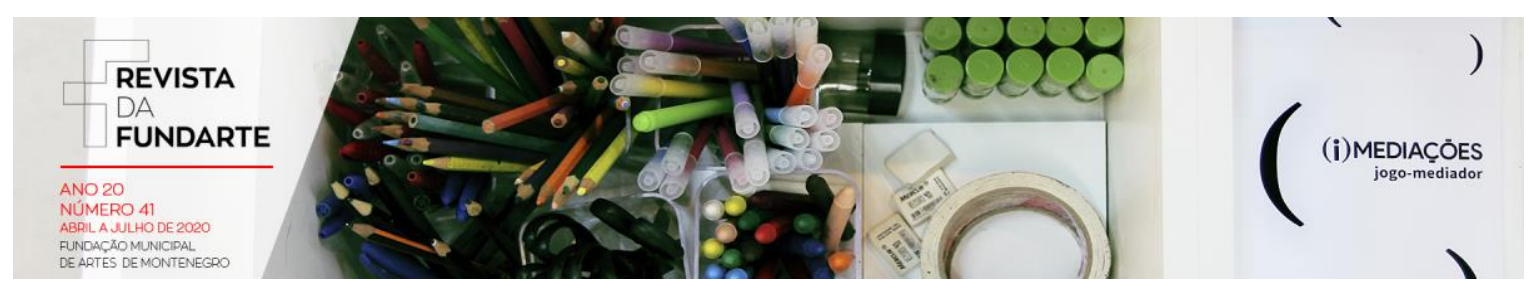

\section{possíveis lacunas e carências em relação a produção acadêmica, fomentando assim, a ampliação da discussão na área.}

Esse artigo faz um levantamento de teses, dissertações, artigos e livros que contém em seu título ou subtítulo a palavra "dança de salão". Para essa pesquisa foram escolhidos como locais de consulta o Catálogo de Teses e Dissertações - CAPES e a Fundação da Biblioteca Nacional.

Assim, este trabalho está dividido em quatro sessões. A primeira traz um breve histórico da dança de salão e sua chegada em território brasileiro. Em um segundo momento, abordaremos sobre a produção científica desenvolvida no âmbito da dança de salão. Na sequência, será apresentada a metodologia utilizada para a pesquisa dos trabalhos e a discussão dos resultados encontrados. Por fim, serão expostas algumas considerações finais sobre $o$ assunto.

\section{A dança de salão e sua chegada no Brasil}

As danças percorreram um longo caminho até se moldarem nos diferentes estilos de dança de salão que foram praticados desde seu surgimento. Por isso, consideramos que essa parte do artigo faz apenas um breve histórico da dança de salão e sua chegada no Brasil.

As danças de salão, ou dança a dois, aparece na Europa, após a idade medieval, no que se denomina período do Renascimento (séc. XIV e XVI). Segundo Perna (2005), a dança de salão surge na Europa e desde o século XV era muito apreciada. Ried (2003) acrescenta que durante a Idade Média e o Renascimento, surgiu a dança como atividade social e, desta forma, as classes nobres e menos

NUNES, Bruno Blois; NASCIMENTO, Flávia Marchi. Produção de conhecimento sobre danças de salão: um levantamento de Livros, Teses e Dissertações no Brasil. Revista da FUNDARTE. Montenegro, p.0120, ano 20, no 41, Abril/Junho de 2020.

Disponível em: http://.seer.fundarte.rs.gov.br/index.php/RevistadaFundarte/index> 30 de junho de 2020. 


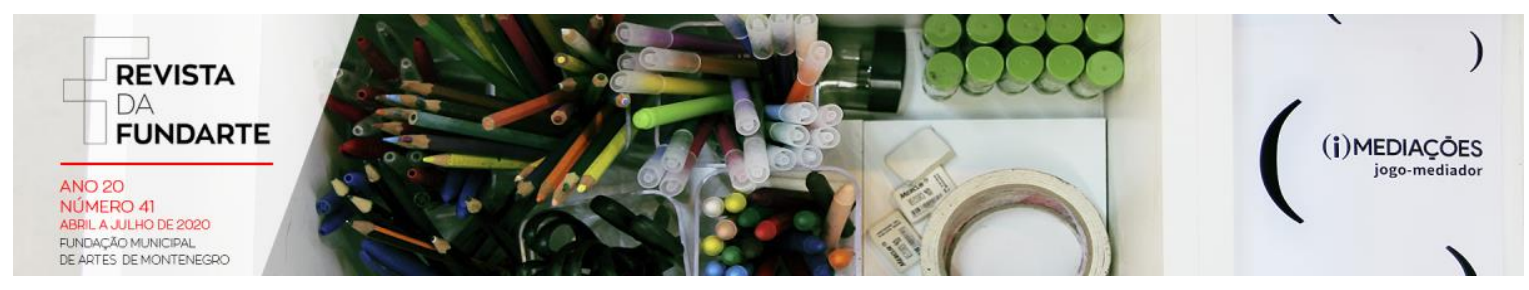

abastadas também se diferenciavam pelo tipo de dança que praticavam, a aristocracia dançava as danças da corte e o povo, as danças folclóricas.

De acordo com Perna (2005) as primeiras danças que chegam ao Brasil no século XVI, através dos portugueses, ainda não tinham como característica o entrelaçamento dos pares. "A primeira dança a dois enlaçada a chegar no Brasil foi a valsa, por volta de 1837" (PERNA, 2005, p. 16, grifo do autor). Sobre a valsa, Ried (2003, p. 09) coloca que "A Valsa Vienense é a mais antiga das danças de salão tradicionais. Já na Idade Média, os pares davam a volta no salão, girando em torno de si mesmo em postura fechada, para finalizar uma rodada de dança".

Perna (2005) relata que a primeira dança a dois de origem em território brasileiro é o maxixe, ${ }^{3}$ por volta de 1870 . É desse último que surge o samba que adentra os salões de dança na década de 1930 com o declínio do maxixe (PERNA, 2005).

Nos dias de hoje, temos inúmeras danças que são praticadas nos salões pelo Brasil: samba, forró, bolero, tango, valsa, zouk, bachata, salsa, cha-cha-cha, sertanejo e soltinho são apenas alguns exemplos. A dança de salão se enquadra tanto na categoria de danças populares pelo fato de se originar "de causas sociais, políticas ou acontecimentos destacados do momento", como também pode ser chamada de dança social, pelo fato de poder "ser praticada com objetivos claros de socialização e diversão por casais, propiciando o estreitamento de relações sociais, de romance e amizade, dentre outras" (PERNA, 2005, p. 10).

Zamoner (2012, p. 1) procura aprimorar a definição sobre dança de salão ao mencionar que ela "é a arte conservacionista que se universaliza em práticas sociais, não cênicas, nem esportivas, consistindo na interpretação improvisada da música,

\footnotetext{
${ }^{3}$ Para quem tiver interesse de investigar o maxixe, os autores indicam a obra intitulada Maxixe: a dança excomungada de Jota Efegê.
}

NUNES, Bruno Blois; NASCIMENTO, Flávia Marchi. Produção de conhecimento sobre danças de salão: um levantamento de Livros, Teses e Dissertações no Brasil. Revista da FUNDARTE. Montenegro, p.0120, ano 20, no 41, Abril/Junho de 2020.

Disponível em: http://.seer.fundarte.rs.gov.br/index.php/RevistadaFundarte/index> 30 de junho de 2020. 


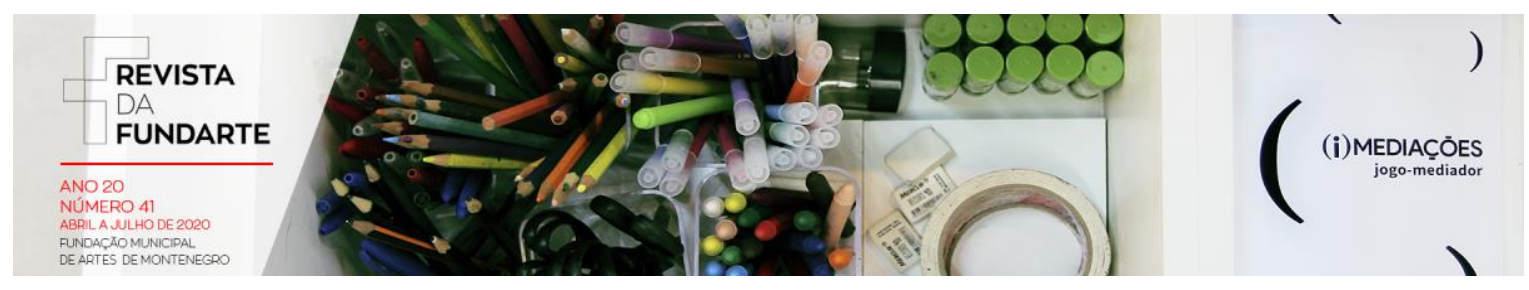

através dos movimentos dos corpos de um casal independente, quando o cavalheiro conduz a dama". Além disso, a mesma autora diferencia a dança de salão da dança social: no caso da dança social, "ocorre de maneira despretensiosa, sem interesse histórico, geográfico e muito menos técnico, atendendo a uma finalidade exclusivamente social, recreativa". Já a dança de salão, "preserva a origem histórica e geográfica, que preserva as características técnicas", trata-se de uma arte (ZAMONER, 2005, p. 39).

\section{Produção científica sobre danças de salão e a metodologia percorrida}

Não é de hoje que a preocupação com a produção de conhecimento na dança de salão se apresenta. Zamoner (2005) já se inquietava com a diminuta produção na área. Essa pouca produtividade é verificada de forma mais claramente, quando se delimita um assunto específico dentro do campo da dança, no caso desse artigo, a dança de salão. Zamoner (2005, p. 91) faz uma crítica forte quanto à produção nessa área: "os livros de dança de salão são poucos. Sobre seu ensino, então, nem se fala. Além de poucos, alguns deles não seguem os padrões mínimos de qualidade científica. Às vezes, nem referências bibliográficas têm".

Instigado por esse levantamento anterior, propomos, no tópico seguinte, explicitar a metodologia usada para o levantamento dos trabalhos que abordam a dança de salão. Este trabalho surge a partir do projeto de pesquisa intitulado Estudos Teóricos e Práticos em Danças de Salão 4 do Curso de Dança-Licenciatura da Universidade Federal de Pelotas (UFPel). Sentimos necessidade de um estudo sobre a

${ }^{4} \mathrm{O}$ referido projeto foi coordenado pela professora Flávia Marchi Nascimento e faz parte do Grupo de Pesquisa OMEGA - Observatório de Memória, Educação, Gesto e Arte. Para maiores informações: https://wp.ufpel.edu.br/omega/.

NUNES, Bruno Blois; NASCIMENTO, Flávia Marchi. Produção de conhecimento sobre danças de salão: um levantamento de Livros, Teses e Dissertações no Brasil. Revista da FUNDARTE. Montenegro, p.0120, ano 20, no 41, Abril/Junho de 2020.

Disponível em: http://.seer.fundarte.rs.gov.br/index.php/RevistadaFundarte/index> 30 de junho de 2020. 


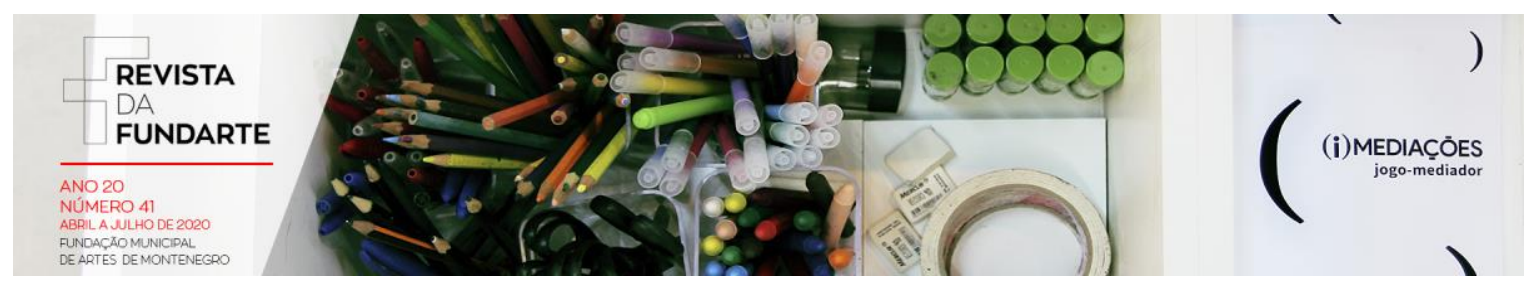

produção científica sobre as danças de salão, buscando perceber possíveis lacunas na produção e incentivar mais produções sobre este gênero de dança.

Desse modo, a pesquisa foi realizada em duas fontes de consulta, de maneira concomitante, no mês de junho de 2019. Foram selecionadas teses e dissertações, no Catálogo de Teses e Dissertações da Capes, ${ }^{5}$ e livros, no site da Fundação da Biblioteca Nacional. Em ambas as fontes de pesquisa, foi utilizada a seguinte palavrachave: "dança de salão", que deveria aparecer no título ou subtítulo de livros, teses e dissertações.

Ficou estabelecido, como local de consulta para as teses e dissertações, o Catálogo de Teses e Dissertações da Capes. Essa escolha deu-se pela confiança que pode ser depositada nessa fonte de pesquisa, amplamente utilizada em estudos científicos.

Para a pesquisa dos livros de dança de salão foi feita uma consulta online dentro do site da Fundação Biblioteca Nacional, também chamada de Biblioteca Nacional do Brasil, para realização de um levantamento de livros dentro do acervo, que contém em seu título ou subtítulo a palavra "dança de salão".

Em 14 de dezembro de 2004, foi decretada a Lei № 10.994, que trata sobre o depósito legal ${ }^{6}$ de publicações nacionais na Fundação da Biblioteca Nacional. A partir desse momento, tornou-se obrigatório o envio de um ou mais exemplares à Biblioteca

5 "O Catálogo de Teses e Dissertações da Capes da Coordenação de Aperfeiçoamento de Pessoal de Nível Superior (CAPES) é um sistema de busca bibliográfica, que reúne registros desde 1987. Possui como referência a Portaria no 13/2006, que institui a divulgação digital das teses e dissertações produzidas pelos programas de doutorado e mestrado reconhecidos" (CAPES, 2017, p. s/p.).

${ }^{6}$ De acordo com o próprio site da Biblioteca Nacional, o depósito legal "é definido pelo envio obrigatório de no mínimo um exemplar de todas as publicações em território nacional, por qualquer meio ou processo, para distribuição gratuita ou venda, no prazo máximo de 30 dias após sua publicação (FUNDAÇÃO BIBLIOTECA NACIONAL, 2017, p. s/p). Informação disponível em: <https://www.bn.gov.br/sobre-bn/deposito-legal>. Acesso em: 03 mar. 2019.

NUNES, Bruno Blois; NASCIMENTO, Flávia Marchi. Produção de conhecimento sobre danças de salão: um levantamento de Livros, Teses e Dissertações no Brasil. Revista da FUNDARTE. Montenegro, p.0120, ano 20, no 41, Abril/Junho de 2020.

Disponível em: http://.seer.fundarte.rs.gov.br/index.php/RevistadaFundarte/index> 30 de junho de 2020. 


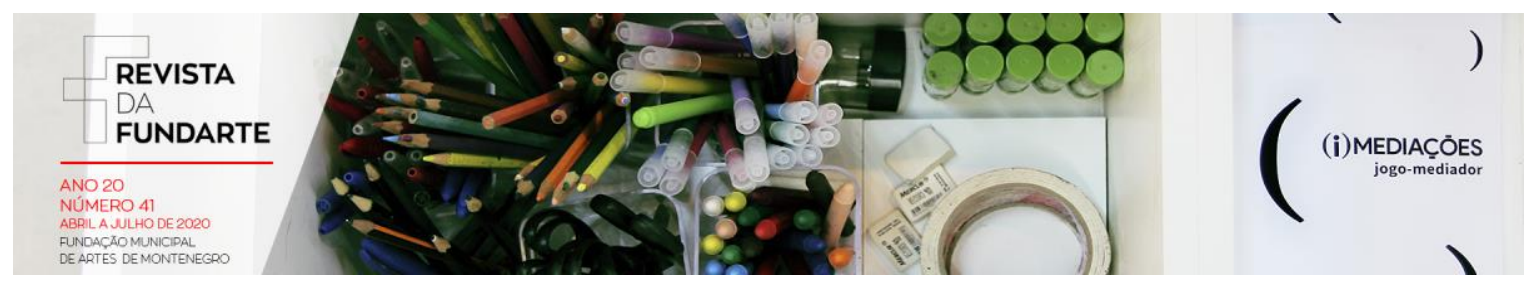

Nacional, que asseguraria a "coleta, a guarda e a difusão da produção intelectual brasileira, visando à preservação e formação da Coleção Memória Nacional" (FUNDAÇÃO BIBLIOTECA NACIONAL, 2017, p. s/p). Devido a isso, acreditamos ser um local importante para a pesquisa desse tipo de material.

\section{Discussão dos resultados}

No Catálogo de Teses e Dissertações da CAPES foram localizados 36 trabalhos entre teses e dissertações que continham em seu título as palavras "dança de salão" (29 de mestrado e 7 de doutorado). Logo abaixo elaboramos um gráfico dividindo o total de trabalhos encontrados nas grandes áreas do conhecimento, de acordo com a classificação do Conselho Nacional de Desenvolvimento Científico e Tecnológico $(\mathrm{CNPq}){ }^{7}$

\footnotetext{
${ }^{7}$ A tabela de áreas do conhecimento está disponível em: <http://www.cnpq.br/documents/10157/186158/TabeladeAreasdoConhecimento.pdf>. Acesso em: $30 \mathrm{abr}$. 2019.
}

NUNES, Bruno Blois; NASCIMENTO, Flávia Marchi. Produção de conhecimento sobre danças de salão: um levantamento de Livros, Teses e Dissertações no Brasil. Revista da FUNDARTE. Montenegro, p.0120, ano 20, no 41, Abril/Junho de 2020.

Disponível em: http://.seer.fundarte.rs.gov.br/index.php/RevistadaFundarte/index> 30 de junho de 2020. 


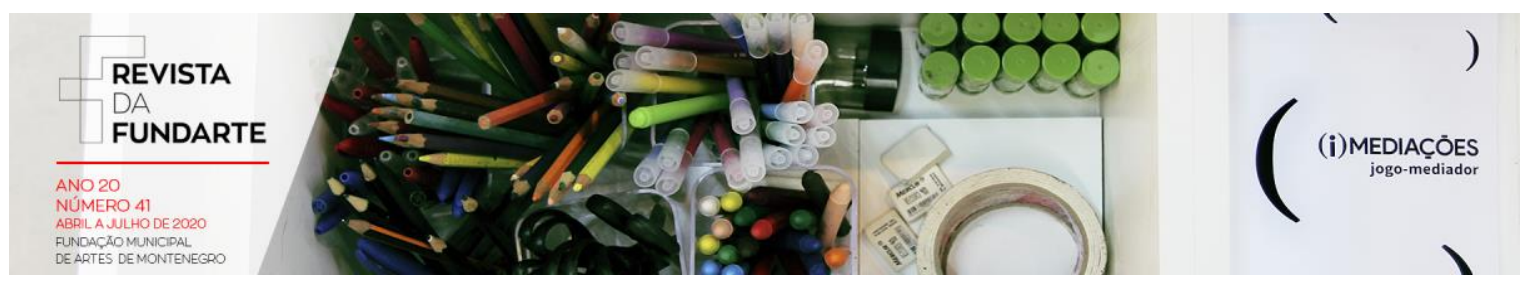

\section{Produção acadêmica - dança de salão (CAPES) - Total de 36 trabalhos}

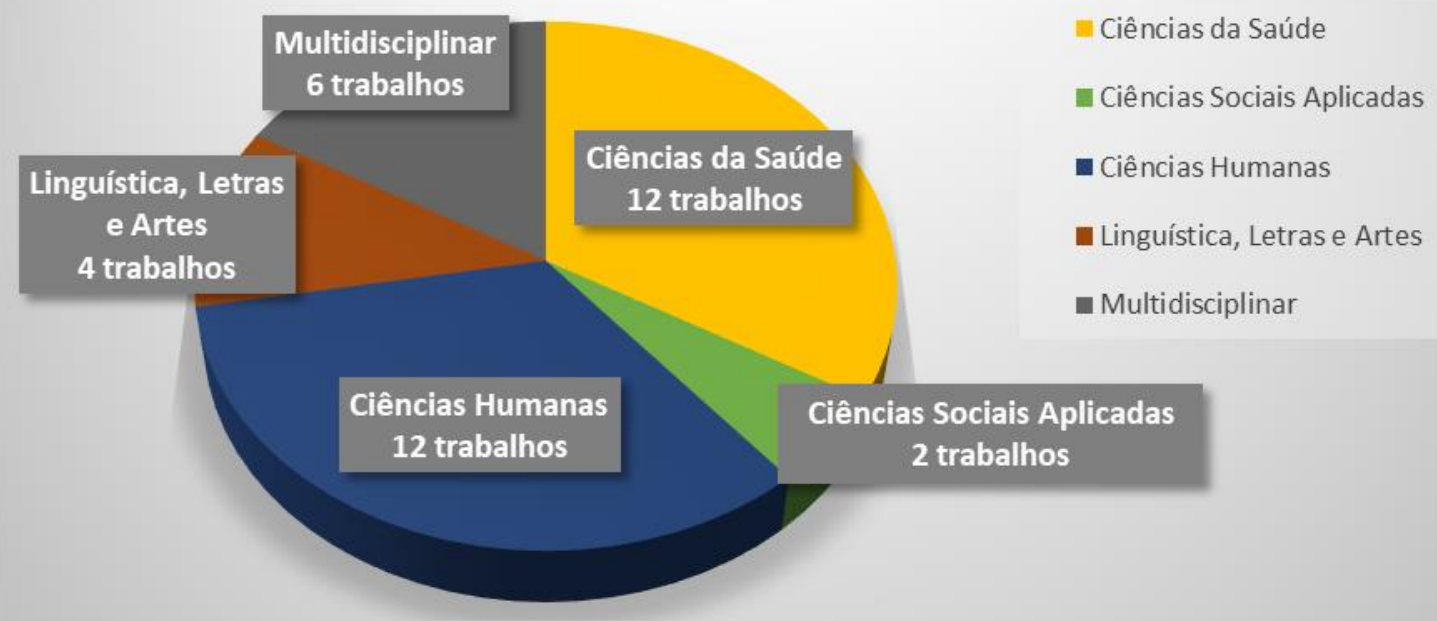

Figura 1: Divisão dos trabalhos de acordo com as Grandes Áreas do CNPq.

Fonte: Elaborado pelos autores (2019).

Primeiramente, é importante salientar que cinco resultados foram alocados na área Multidisciplinar. Essa iniciativa foi necessária pelo fato da possibilidade de alguns trabalhos serem classificados em mais de uma grande área do conhecimento.

Como podemos ver na Figura 1, a maioria dos trabalhos que continham em seu título ou subtítulo a palavra "dança de salão" são das Ciências Humanas e das Ciências da Saúde (ambos com 12 trabalhos no total). Abaixo mostramos as produções nas subáreas do conhecimento:

NUNES, Bruno Blois; NASCIMENTO, Flávia Marchi. Produção de conhecimento sobre danças de salão: um levantamento de Livros, Teses e Dissertações no Brasil. Revista da FUNDARTE. Montenegro, p.0120, ano 20, no 41, Abril/Junho de 2020.

Disponível em: http://.seer.fundarte.rs.gov.br/index.php/RevistadaFundarte/index> 30 de junho de 2020. 


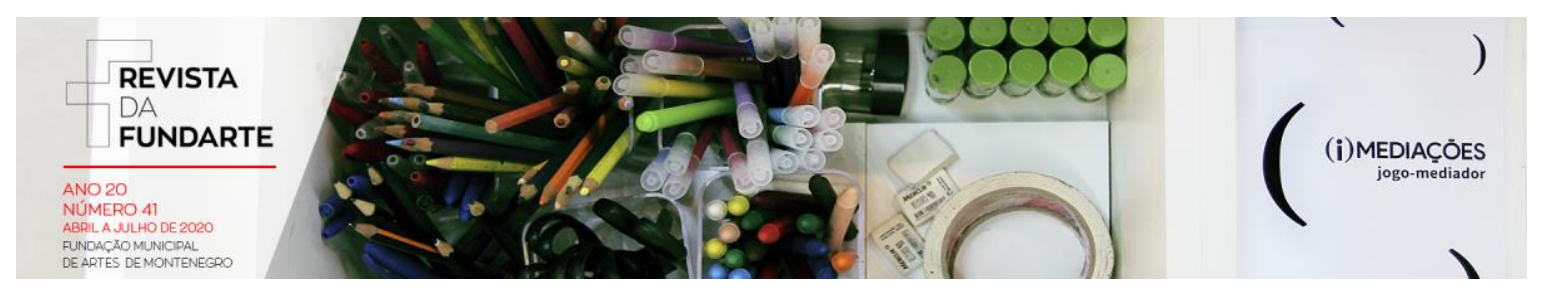

\begin{tabular}{|c|c|c|}
\hline Grandes Áreas & Subáreas & Total de Produções \\
\hline \multirow{3}{*}{ Ciências da Saúde } & Educação Física & 08 \\
\hline & Lazer & 01 \\
\hline & Medicina & 03 \\
\hline $\begin{array}{ll}\text { Ciências } & \text { Sociais } \\
\text { Aplicadas } & \end{array}$ & Administração & 02 \\
\hline \multirow[t]{5}{*}{ Ciências Humanas } & Educação & 03 \\
\hline & Psicologia & 04 \\
\hline & Sociologia & 03 \\
\hline & Sociologia e Antropologia & 01 \\
\hline & Teologia & 01 \\
\hline $\begin{array}{l}\text { Linguística, Letras e } \\
\text { Artes }\end{array}$ & Artes & 04 \\
\hline \multirow{4}{*}{ Multidisciplinar $^{8}$} & $\begin{array}{c}\text { Ensino de Ciência e } \\
\text { Tecnologia }\end{array}$ & 01 \\
\hline & Ciências do Envelhecimento & 01 \\
\hline & Saúde e Meio Ambiente & 03 \\
\hline & Tecnologia e Sociedade & 01 \\
\hline
\end{tabular}

Quadro 1: Divisão dos trabalhos de acordo com as Grandes Áreas do CNPq, subáreas e o total de produção de cada uma delas.

Fonte: Elaborado pelos autores (2019).

Como é possível observar no Quadro 1, na grande área de Ciências da Saúde, a maioria dos trabalhos encontrados são do campo da Educação Física com 8 trabalhos.

${ }^{8}$ É importante salientar que as subáreas vinculadas à grande área Multidisciplinar se referem aos nomes dos programas ou titulações que foram defendidos com os respectivos trabalhos.

NUNES, Bruno Blois; NASCIMENTO, Flávia Marchi. Produção de conhecimento sobre danças de salão: um levantamento de Livros, Teses e Dissertações no Brasil. Revista da FUNDARTE. Montenegro, p.0120, ano 20, no 41, Abril/Junho de 2020.

Disponível em: http://.seer.fundarte.rs.gov.br/index.php/RevistadaFundarte/index> 30 de junho de 2020. 


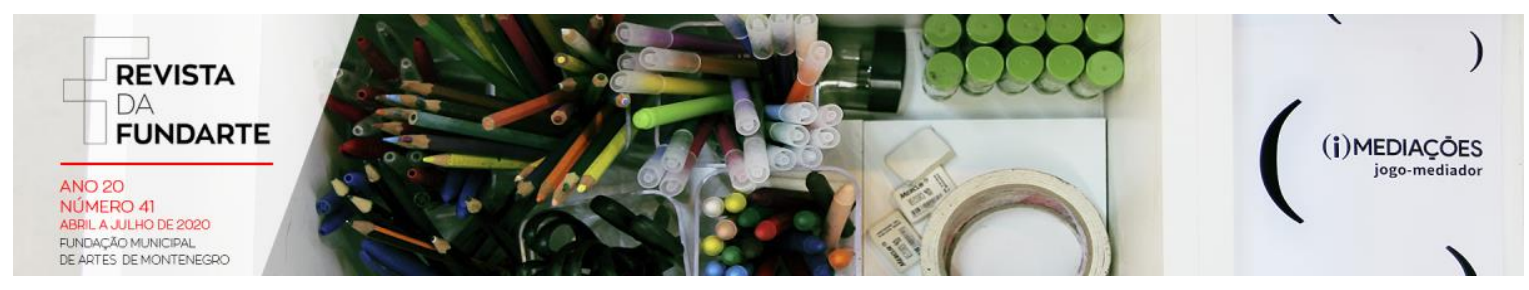

Essa produção sobre o tema, no campo da Educação Física, se deve pela dança ser conteúdo da mesma e também, por sua trajetória ser mais antiga, se comparada com a formação acadêmica em dança. Além disso, é possível observar no estatuto do Conselho Federal de Educação Física (CONFEF) o seguinte:

O Profissional de Educação Física é especialista em atividades físicas, nas suas diversas manifestações - ginásticas, exercícios físicos, desportos, jogos, lutas, capoeira, artes marciais, danças, atividades rítmicas, expressivas e acrobáticas, musculação, lazer, recreação, reabilitação, ergonomia, relaxamento corporal, ioga, exercícios compensatórios à atividade laboral e do cotidiano e outras práticas corporais [...] (BRASIL, 2010, p. 137, grifo nosso).

É possível perceber na citação acima que a dança e, consequentemente, a dança de salão mantêm um forte vínculo com o campo da Educação Física. Embora o campo científico da dança tenha se estabelecido pela década de 1990, como mencionamos anteriormente, grande parte das produções acadêmicas, que foram encontradas em nosso levantamento, é feito dentro da Educação Física.

Dos oito estudos na área da Educação Física, dois tinham como público alvo a população idosa. Quadros Júnior (2008) - analisar os efeitos de um programa de dança de salão em idosos verificando sua memória e estado cognitivo, além de outros aspectos. Coelho (2017) - trata do envelhecimento, a velhice e a dança de salão. Em um primeiro momento, a autora analisa a problemática da velhice e a dança de salão no filme Chega de Saudade de 2008 dirigido por Laís Bodanzky. Em um segundo momento, a autora faz uma pesquisa de campo em um centro de convivência de idosos, e entrevistou aqueles que praticavam dança de salão, cujas respostas foram de ganhos obtidos nas esferas físicas, psíquicas e sociais.

Dois estudos tratam de participantes que se encontram em um estágio inicial de contato com a dança de salão. Fonseca (2008) investiga os efeitos da dança de salão

NUNES, Bruno Blois; NASCIMENTO, Flávia Marchi. Produção de conhecimento sobre danças de salão: um levantamento de Livros, Teses e Dissertações no Brasil. Revista da FUNDARTE. Montenegro, p.0120, ano 20, no 41, Abril/Junho de 2020.

Disponível em: http://.seer.fundarte.rs.gov.br/index.php/RevistadaFundarte/index> 30 de junho de 2020. 


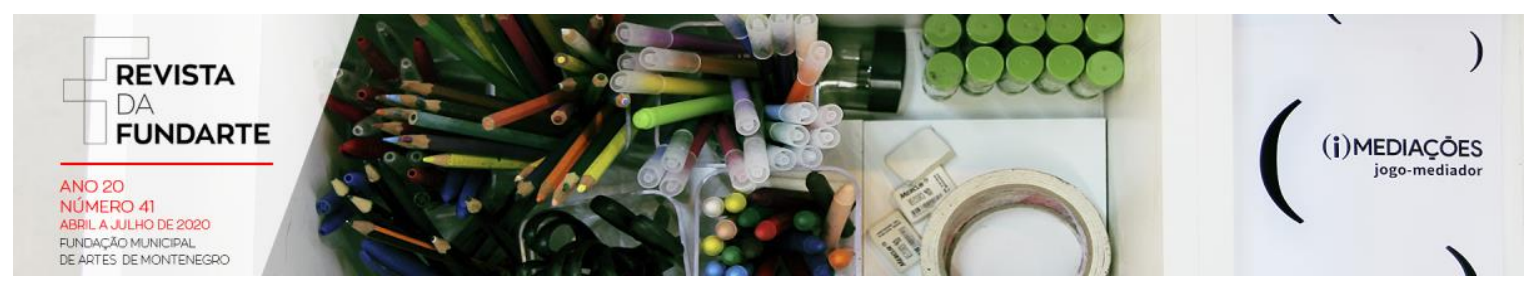

no esquema corporal ${ }^{9}$ e na imagem corporal ${ }^{10}$ de indivíduos iniciantes, além de analisar os aspectos motivacionais, que fazem com que as pessoas busquem a dança de salão, como também, se mantenham nessa prática. Já Maia (2009) pesquisa a influência de um programa de iniciação em dança de salão na escola sobre o desempenho motor dos escolares.

Outros dois estudos fazem uma relação bem específica entre a saúde e dança de salão. Gonzáles (2014) revela que, por meio de um estudo em coronariopatas e hipertensos, esses grupos que praticam dança de salão têm menor prevalência e apresentaram baixo risco de disfunção erétil e disfunção sexual, se comparados a grupos que não a praticavam. Cardoso (2017) tem seu enfoque voltado na análise da qualidade de vida, fadiga e lesões em bailarinos brasileiros, profissionais de dança de salão.

Os últimos dois estudos encontrados que foram desenvolvidos na área da Educação Física têm focos distintos. Almeida (1998) revela a presença da prática da dança de salão na sociedade carioca, como atividade de lazer desde o século XIX. Já Vecchi (2011) procura identificar como se dá o ato de ensinar dança de salão, embasando-se nos discursos dos próprios professores, utilizando o Teaching for Understanding (TFU). ${ }^{11}$

No entanto, é importante ressaltar que foram encontrados trabalhos sobre dança de salão na grande área Linguística, Letras e Artes. O que é mais relevante nesse caso

\footnotetext{
9 “[...] é um componente neurológico que permite ao indivíduo ter consciência dos segmentos corporais e posição que seu corpo ocupa no espaço" (FONSECA, 2008, p. xi).

10 "[...] é um componente psíquico que representa a imagem mental que o indivíduo tem de si mesmo" (FONSECA, 2008, p. xi).

11 O Teaching for Understanding é uma ferramenta que procura auxiliar a compreensão dos alunos nas salas de aula de uma maneira mais acessível. É um método que traz em seu repertório "recursos e estratégias para envolver os alunos em experiências de aprendizagem significativas e duradouras" (BLYTHE, 1998, p. s/p.).
}

NUNES, Bruno Blois; NASCIMENTO, Flávia Marchi. Produção de conhecimento sobre danças de salão: um levantamento de Livros, Teses e Dissertações no Brasil. Revista da FUNDARTE. Montenegro, p.0120, ano 20, no 41, Abril/Junho de 2020.

Disponível em: http://.seer.fundarte.rs.gov.br/index.php/RevistadaFundarte/index> 30 de junho de 2020. 


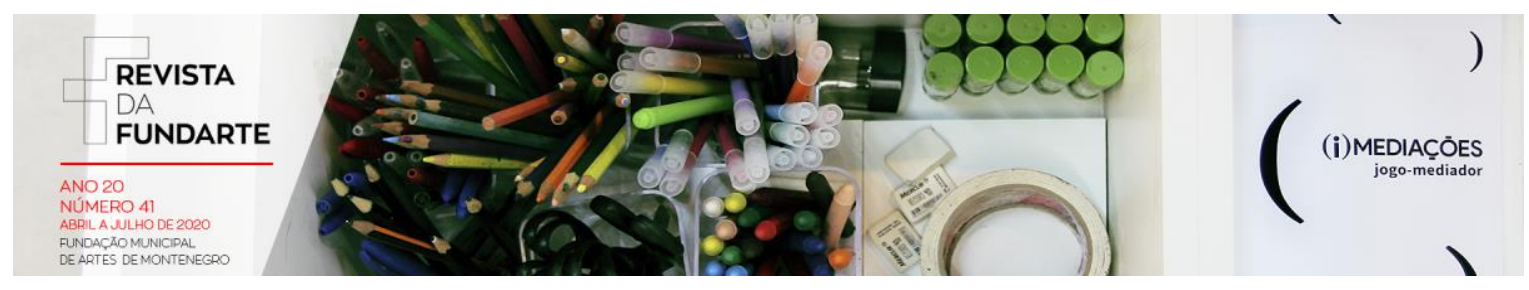

é que os 4 trabalhos desenvolvidos são da subárea das Artes, o que demonstra o início de uma trajetória de produção acadêmica sobre o assunto na área.

Souza (2010) discute o universo simbólico dos espaços de dança de salão. A autora mostra que esses espaços são preenchidos "por um conjunto complexo de discursos e ações que traduzem memórias, adaptações, inovações e tradições, que dialogam e se transformam, conforme o fluxo de entradas e saídas de novos atores sociais" (SOUZA, 2010, p. 06-07).

Strack (2017) problematiza o papel das mulheres na dança de salão. A autora analisa a condução na dança de salão desenvolvendo um estágio evolutivo por meio de uma divisão em seis territórios: $\left.1^{\circ}\right)$ condução tradicional, $2^{\circ}$ ) os enfeites, $3^{\circ}$ ) silêncios na condução, 4º) influência do seguidor, 5ํ) diálogo corporal até chegar ao último território intitulado comunhão em que ocorre uma dissolução completa da condução tradicional.

Abreu (2011) analisa o processo criativo e as relações entre criação e técnica desenvolvidas em uma academia do Rio de Janeiro. Quintanilha (2017) também enfoca o aspecto criativo na dança de salão, além de debater as questões de gênero e a exploração de objetos nos processos de criação.

Além do Catálogo de Teses de Dissertações - CAPES, outro local de consulta foi a Fundação Biblioteca Nacional. Foram encontrados, dentro do catálogo geral de obras da Biblioteca Nacional, 16 livros que continham em seu título ou subtítulo a palavra-chave "dança de salão". Abaixo, segue o quadro com as obras encontradas durante o levantamento:

\begin{tabular}{|l|l|l|}
\hline AUTOR & OBRA & ANO \\
\hline CANUTO, Marcos. & $\begin{array}{l}\text { Princípios pedagógicos para a } \\
\text { dança de salão }\end{array}$ & 2004 \\
\hline GRANGEIRO, Marcelo. & Ai, pisaram no meu pé!: um novo & 2014 \\
\hline
\end{tabular}

NUNES, Bruno Blois; NASCIMENTO, Flávia Marchi. Produção de conhecimento sobre danças de salão: um levantamento de Livros, Teses e Dissertações no Brasil. Revista da FUNDARTE. Montenegro, p.0120, ano 20, no 41, Abril/Junho de 2020.

Disponível em: http://.seer.fundarte.rs.gov.br/index.php/RevistadaFundarte/index> 30 de junho de 2020. 


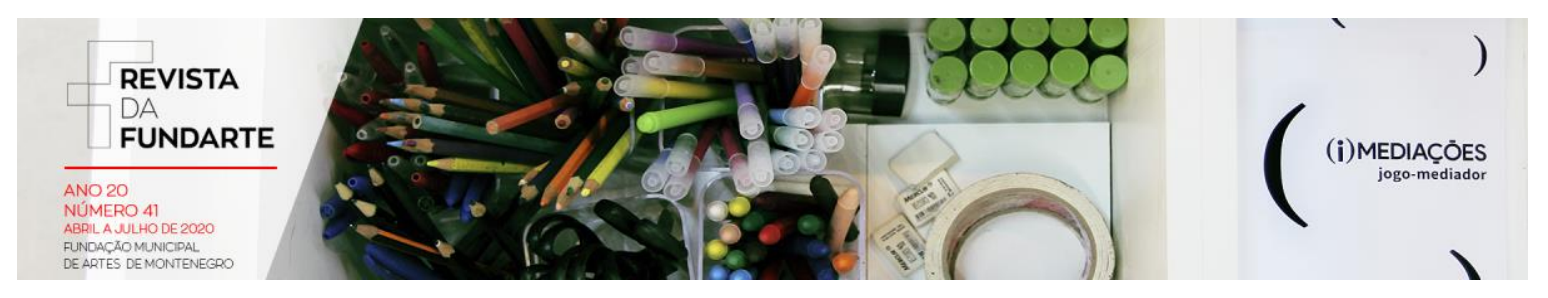

\begin{tabular}{|c|c|c|}
\hline & $\begin{array}{l}\text { conceito em aprendizagem e ensino } \\
\text { na dança de salão. }\end{array}$ & \\
\hline $\begin{array}{l}\text { ORTIZ, Paula Emboava; } \\
\text { ROSA, Marcelo Victor } \\
\text { da. }\end{array}$ & $\begin{array}{l}\text { O ensino da dança de salão com } \\
\text { base na abordagem crítico- } \\
\text { emancipatória. }\end{array}$ & 2015 \\
\hline $\begin{array}{l}\text { PERNA, Marco A. } \\
\text { (Org.). }\end{array}$ & $\begin{array}{l}200 \text { Anos de Dança de Salão no } \\
\text { Brasil - vol. } 1 \text {. }\end{array}$ & 2011 \\
\hline $\begin{array}{l}\text { PERNA, Marco A. } \\
\text { (Org.). }\end{array}$ & $\begin{array}{l}200 \text { Anos de Dança de Salão no } \\
\text { Brasil - vol. } 2 \text {. }\end{array}$ & 2012 \\
\hline $\begin{array}{lll}\text { PERNA, Marco } & \text { A. } \\
\text { (Org.). } & & \\
\end{array}$ & $\begin{array}{l}200 \text { Anos de Dança de Salão no } \\
\text { Brasil - vol. } 3 \text {. }\end{array}$ & 2012 \\
\hline PERNA, Marco A. & $\begin{array}{l}\text { Samba de gafieira: a história da } \\
\text { dança de salão brasileira. }\end{array}$ & 2002 \\
\hline REIS, Elaine. & $\begin{array}{l}\text { Pé de valsa - o reverso da moeda: } \\
\text { vivência de uma empresária da dança } \\
\text { de salão. }\end{array}$ & 2013 \\
\hline $\begin{array}{l}\text { ROSA, Marcelo Victor } \\
\text { da et al. (Org.). }\end{array}$ & $\begin{array}{l}\text { Dança de salão: } \\
\text { diferentes temáticas. }\end{array}$ & 2014 \\
\hline $\begin{array}{l}\text { RUTHES, Sandra } \\
\text { Elena. }\end{array}$ & Música para dança de salão. & 2007 \\
\hline SANTANA, Mary. & A crianca e a danca de salão. & 2007 \\
\hline SILVA JUNIOR, João. & $\begin{array}{l}\text { O homem na dança de salão: visões, } \\
\text { percepções e motivações. }\end{array}$ & 2010 \\
\hline $\begin{array}{l}\text { VASCONCELOS, } \\
\text { Denise Silva. }\end{array}$ & $\begin{array}{l}\text { De volta aos embalos de sábado à } \\
\text { noite: a dança de salão na terceira } \\
\text { idade. }\end{array}$ & 2012 \\
\hline ZAMONER, Maristela. & $\begin{array}{l}\text { Dança de salão: a caminho da } \\
\text { licenciatura. }\end{array}$ & 2005 \\
\hline ZAMONER, Maristela. & $\begin{array}{l}\text { Educação ambiental na dança de } \\
\text { salão. }\end{array}$ & 2007 \\
\hline ZAMONER, Maristela. & Sexo e dança de salão. & 2007 \\
\hline
\end{tabular}

Quadro 2: Levantamento feito na Fundação Biblioteca Nacional.

Fonte: Elaborado pelos autores (2019).

Em trabalho publicado em 2010, Maristela Zamoner fez um levantamento semelhante na Fundação da Biblioteca Nacional no que se refere aos livros. A pesquisa

NUNES, Bruno Blois; NASCIMENTO, Flávia Marchi. Produção de conhecimento sobre danças de salão: um levantamento de Livros, Teses e Dissertações no Brasil. Revista da FUNDARTE. Montenegro, p.0120, ano 20, no 41, Abril/Junho de 2020.

Disponível em: http://.seer.fundarte.rs.gov.br/index.php/RevistadaFundarte/index> 30 de junho de 2020. 


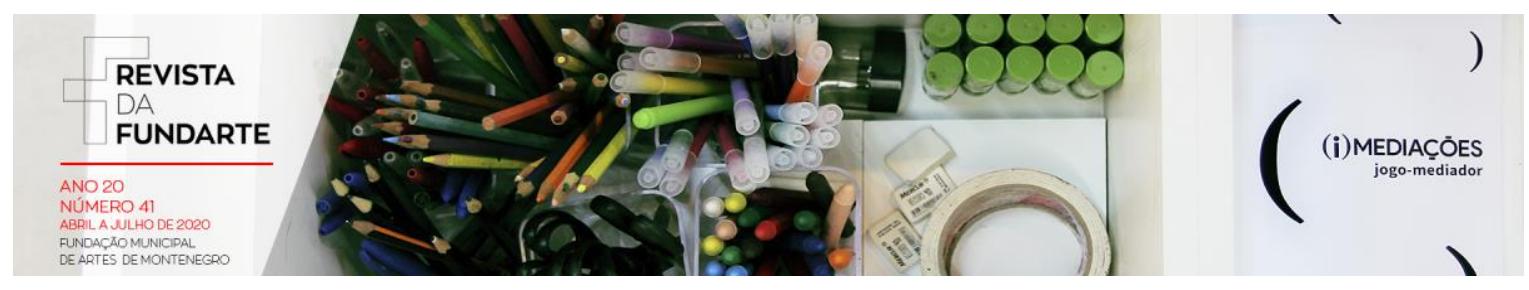

da autora foi desenvolvida através da pesquisa da palavra-chave dança de salão, no campo assunto, no site da Biblioteca Nacional. Nesse período em que foi realizada a busca foram encontrados 14 títulos (ZAMONER, 2010, p. 1).

Analisando o levantamento realizado na Fundação da Biblioteca Nacional por Zamoner (2010), a qual encontrou apenas 14 livros com o assunto sobre dança de salão, e comparando com esse estudo que localizou 16 livros que incluíam em seu título ou subtítulo a palavra "dança de salão", notamos uma produção muito escassa desse material que durante os quase últimos dez anos, não mostrou nenhum salto quantitativo.

Outro dado interessante é que praticamente metade dos trabalhos (7 de 16 livros) correspondem, como podemos ver no Quadro 2, a apenas dois autores: Marco Antonio Perna (com 4 trabalhos) e Maristela Zamoner (com 3 trabalhos). Isso mostra que a produção na área de dança, mais especificamente na dança de salão, ainda é realizada por poucos pesquisadores.

Um último ponto importante a ressaltar são as distintas áreas em que esses autores trabalham ou tiveram sua formação acadêmica: Marco Antonio Perna (formação na Engenharia Fotográfica e fotógrafo), Maristela Zamoner (formação na Biologia) e Marcelo Grangeiro e Sandra Elena Ruthes (formação na área de Educação Física). Isso revela que, pelo curso acadêmico de dança ser ainda considerado um curso novo, muito da discussão sobre dança de salão acaba partindo de pessoas formadas em outras áreas acadêmicas, com vivência em dança de salão.

NUNES, Bruno Blois; NASCIMENTO, Flávia Marchi. Produção de conhecimento sobre danças de salão: um levantamento de Livros, Teses e Dissertações no Brasil. Revista da FUNDARTE. Montenegro, p.0120, ano 20, no 41, Abril/Junho de 2020.

Disponível em: http://.seer.fundarte.rs.gov.br/index.php/RevistadaFundarte/index> 30 de junho de 2020. 


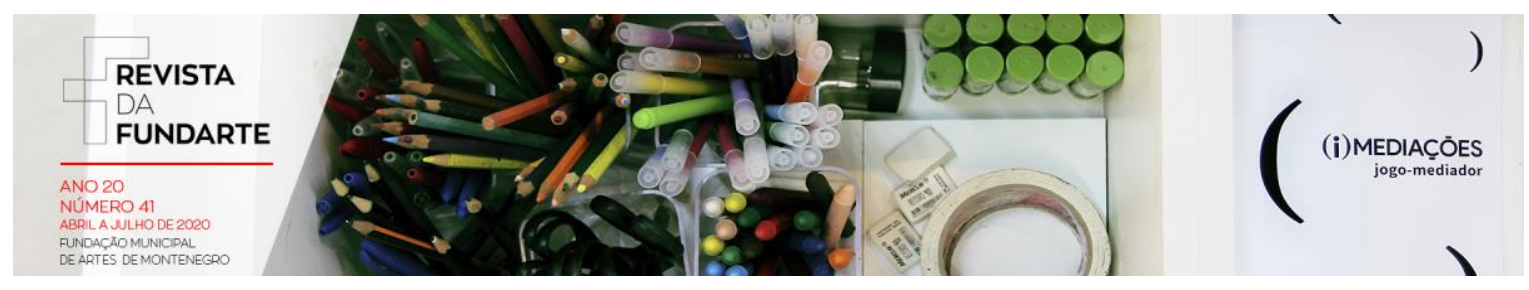

\section{Considerações finais}

O levantamento realizado nesse estudo demonstrou que a produção acadêmica em dança de salão é escassa. Tanto o Catálogo de Teses e Dissertações - CAPES, quanto a Fundação Biblioteca Nacional contém limitado referencial teórico sobre o assunto.

Os resultados desse estudo revelam o caráter híbrido da dança de salão no campo acadêmico. Embora tenha se constatado um pequeno número de pesquisas sobre o assunto, a dança de salão transitou por subáreas como Educação Física, Medicina, Psicologia, Educação, Artes e a Administração, revelando seu perfil heterogêneo, como objeto de estudo.

Mesmo na subárea em que a dança de salão foi mais debatida (a Educação Física), sua abordagem foi realizada com público e contexto diferentes: educação infantil, população idosa, bailarinos profissionais e metodologia de ensino foram tópicos ressaltados nesses estudos.

No tocante ao levantamento realizado na Fundação Biblioteca Nacional, chama a atenção grande parte das obras serem de autores de outras áreas do conhecimento. Além disso, quase metade dos livros encontrados nesse local (7 obras) foram produções de apenas dois autores o que revela a carência de autores que tratem do tema.

A consolidação da dança de salão no campo acadêmico passa pelo fortalecimento de seus estudos teóricos. Tendo isso em vista, gostaríamos de instigar os pesquisadores da área a problematizar o assunto em pesquisas futuras.

NUNES, Bruno Blois; NASCIMENTO, Flávia Marchi. Produção de conhecimento sobre danças de salão: um levantamento de Livros, Teses e Dissertações no Brasil. Revista da FUNDARTE. Montenegro, p.0120, ano 20, no 41, Abril/Junho de 2020.

Disponível em: http://.seer.fundarte.rs.gov.br/index.php/RevistadaFundarte/index> 30 de junho de 2020. 


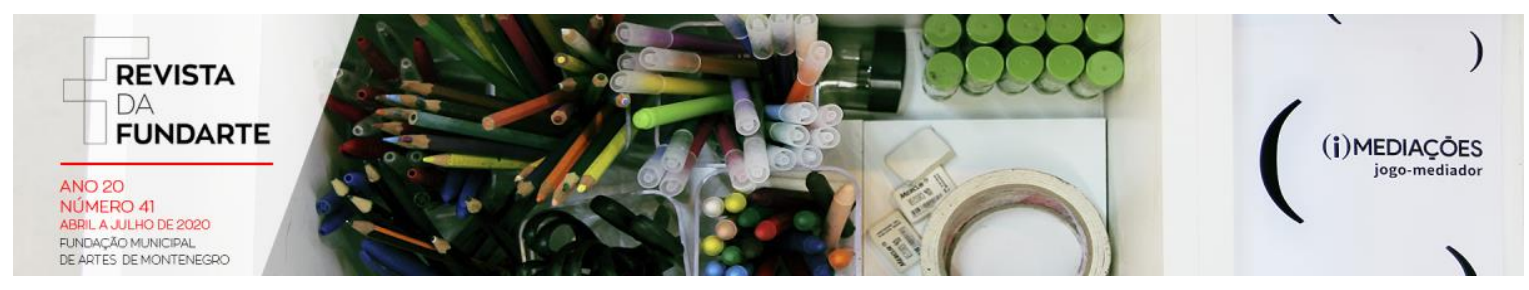

\section{Referências:}

ABREU, Fernanda Ferreira de. A mulher na dança de salão: sociabilidade, ensino e criação. 2011. 124p. Dissertação (Mestrado em Ciências da Arte), Faculdade de Artes, Universidade Federal Fluminense, Niterói, 2011.

ALMEIDA, Rita de Cássia Miranda Jordão de. Dança de salão na cultura e no lazer do Rio de Janeiro no período de 1870-1998. 1998. 158p. Dissertação (Mestrado em Educação Física), Pós-Graduação em Educação Física, Universidade Gama Filho, Rio de Janeiro, 1998.

ARAÚJO, Alceu Maynard. Folclore Nacional Il: danças, recreação e música. 3. ed. São Paulo: Martins Fontes, 2004.

BLYTHE, Tina et al. The Teaching for Understanding Guide. San Francisco (USA): Jossey-Bass, 1998.

BRASIL. Conselho Federal de Educação Física. Resolução oํ 206, de 7 de novembro de 2010. Diário Oficial da União, Brasília, DF, 13 dez. 2010. Seção 1, p. 137-143.

Disponível em:

$<$ http://pesquisa.in.gov.br/imprensa/isp/visualiza/index.jsp?data=13/12/2010\&jornal=1\&p agina=143\&totalArquivos=144> . Acesso em: 14 abr. 2019.

CARDOSO, Allana Alexandre. Dança de salão no Brasil: aspectos multifatoriais de bailarinos profissionais. 2017. Dissertação (Mestrado em Ciências do Movimentos Humano), Centro de Ciências da Saúde e do Esporte, Universidade do Estado de Santa Catarina, Florianópolis, 2017.

COELHO, Lúcia Aparecida Martins Campos. Nas telas de cinema e nas salas de dança de salão: a vez e a voz das idosas. 2017. 121p. Tese (Doutorado em Ciências do Exercício e do Esporte), Pós-Graduação em Ciências do Exercício e do Esporte, Universidade do Estado do Rio de Janeiro, Rio de Janeiro, 2017.

NUNES, Bruno Blois; NASCIMENTO, Flávia Marchi. Produção de conhecimento sobre danças de salão: um levantamento de Livros, Teses e Dissertações no Brasil. Revista da FUNDARTE. Montenegro, p.0120, ano 20, no 41, Abril/Junho de 2020.

Disponível em: http://.seer.fundarte.rs.gov.br/index.php/RevistadaFundarte/index> 30 de junho de 2020. 


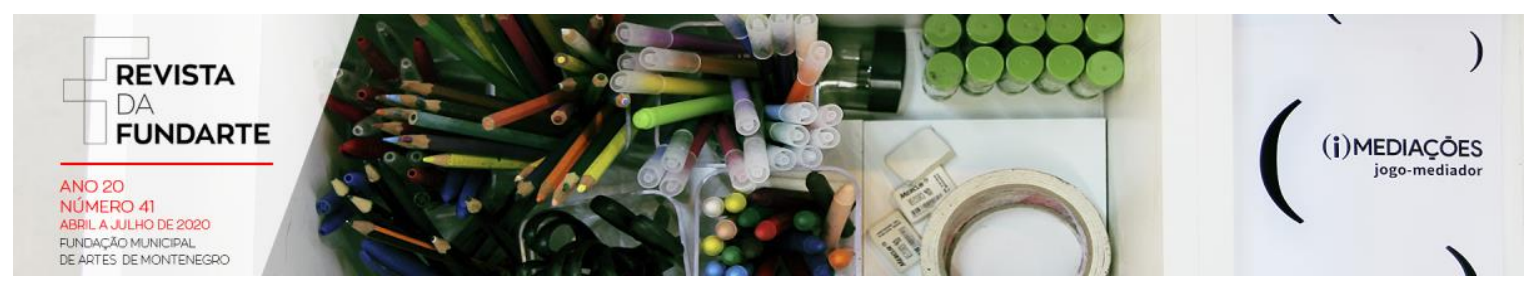

COORDENAÇÃO DE APERFEIÇOAMENTO DE PESSOAL DE NÍVEL SUPERIOR (CAPES). Como funciona o Catálogo de Teses e Dissertações da Capes? Brasília, 17 nov. 2017. Disponível em: <http://www.capes.gov.br/acessoainformacao/perguntasfrequentes/periodicos/3571-como-funciona-o-banco-de-teses $>$. Acesso em: 01 jun. 2019.

CORRÊA, Josiane Franken; NASCIMENTO, Flávia Marchi. Ensino de dança no Rio Grande do Sul: um breve panorama. Conceição, Campinas, v.2, n.2, p.53-68, jul./dez. 2013. Disponível em: <https://periodicos.sbu.unicamp.br/ojs/index.php/conce/article/view/8647702/14581>. Acesso em: 27 mar. 2019.

FONSECA, Cristiane Costa. Análise do esquema corporal e imagem corporal na dança de salão e seus aspectos motivacionais. 2008. 90p. Dissertação (Mestrado em Educação Física. Pós-Graduação em Educação Física, Universidade São Judas Tadeu, São Paulo, 2008. Disponível em: $<$ http://www.dominiopublico.gov.br/pesquisa/DetalheObraForm.do?select action=\&co 0 $\underline{\text { bra }=134624}$ >. Acesso em: 14 jun. 2019.

FUNDAÇÃO BIBLIOTECA NACIONAL. Depósito Legal. 2017. Disponível em: <https://www.bn.gov.br/sobre-bn/deposito-legal>. Acesso em: 03 mar. 2019.

GONZÁLES, Ana Inês. Coronariopatas e hipertensos praticantes de dança de salão apresentam melhor função sexual e aptidão física que participantes de programa de reabilitação e sedentários. 2014. 108p. Dissertação (Mestrado em Ciências do Movimento Humano, Pós-Graduação em Ciências do Movimento Humano, Universidade do Estado de Santa Catarina, Florianópolis, 2014.

MAIA, Maria Aparecida Coimbra. Estudo da influência de um programa centrado na dança de salão sobre o desempenho motor de escolares de 8 a 10 anos de idade. 2009. 184p. Dissertação (Mestrado em Educação Física), Departamento de Educação Física, Universidade Estadual do Maringá, Centro de Educação Física e Esporte, Universidade Estadual de Londrina, 2009. Disponível em: $<$ http://livros01.livrosgratis.com.br/cp112753.pdf>. Acesso em: 28 jun. 2019.

NUNES, Bruno Blois; NASCIMENTO, Flávia Marchi. Produção de conhecimento sobre danças de salão: um levantamento de Livros, Teses e Dissertações no Brasil. Revista da FUNDARTE. Montenegro, p.0120, ano 20, no 41, Abril/Junho de 2020.

Disponível em: http://.seer.fundarte.rs.gov.br/index.php/RevistadaFundarte/index> 30 de junho de 2020. 


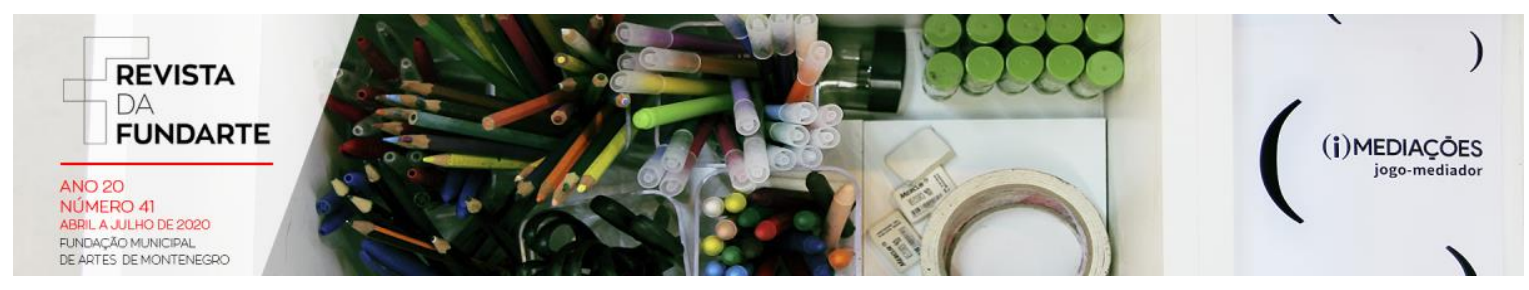

NUNES, Bruno Blois. O Fascínio das Danças de Corte. Curitiba: Appris, 2016.

PERNA, Marco Antonio. Samba de gafieira: a história da dança de salão brasileira. 2 . ed. Rio de Janeiro: Edição do autor, 2005.

PORTINARI, Maribel. História da Dança. Rio de Janeiro: Nova Fronteira, 1989.

QUADROS JÚNIOR, Antonio Carlos de. Dança de salão, funções executivas e memória em idosos institucionalizados. 2008. 113p. Dissertação (Mestrado em Ciências da Motricidade), Instituto de Biociências, Universidade Estadual Paulista, Rio Claro, 2008. Disponível em:

$<$ https://repositorio.unesp.br/bitstream/handle/11449/87426/quadrosjunior ac me rcla.p df? sequence=1\&isAllowed=y >. Acesso em 27 jun. 2019.

QUINTANILHA, Elisa de Brito. Da Dança de Salão à Dança com Objetos - criação em dança. 2017. Dissertação (Mestrado em Estudos Contemporâneos das Artes), Instituto de Artes e Comunicação Social, Universidade Federal Fluminense, Niterói, 2017.

RIED, Bettina. Fundamentos de dança de salão. São Paulo: Phorte, 2003.

SOUZA, Maria Inês Galvão. Espaços de dança de salão no cenário urbano da cidade do Rio de Janeiro: tradição e inovação na cena contemporânea. 2010. 226p. Tese (Doutorado em Artes Cênicas), Centro de Letras e Artes, Universidade Federal do Estado do Rio de Janeiro, Rio de Janeiro, 2010. Disponível em: < http://www.repositorio-bc.unirio.br:8080/xmlui/bitstream/handle/unirio/11425/Tese\%20\%20In\%c3\%aas\%20Galv\%c3\%a30.pdf? sequence=1\&isAllowed=y >. Acesso em: 23 jun. 2019.

STRACK, Míriam Medeiros. Dança de salão: cartografia de uma abordagem feminista. 2017. 126p. Dissertação (Mestrado em Artes), Escola de Belas Artes, Universidade Federal de Minas Gerais, Belo Horizonte, 2017.

VECCHI, Rodrigo Luiz. O ensino da dança de salão pautado na teoria do "Teaching for understanding" (TFU). 2011. 217p. Tese (Doutorado em Educação Física), Faculdade de Educação Física, Universidade São Judas Tadeu, São Paulo, 2011. Disponível em: $<$ https://www.usjt.br/biblioteca/mono disser/mono diss/2012/190.pdf >. Acesso em: 17 jun. 2019.

NUNES, Bruno Blois; NASCIMENTO, Flávia Marchi. Produção de conhecimento sobre danças de salão: um levantamento de Livros, Teses e Dissertações no Brasil. Revista da FUNDARTE. Montenegro, p.0120, ano 20, no 41, Abril/Junho de 2020.

Disponível em: http://.seer.fundarte.rs.gov.br/index.php/RevistadaFundarte/index> 30 de junho de 2020. 


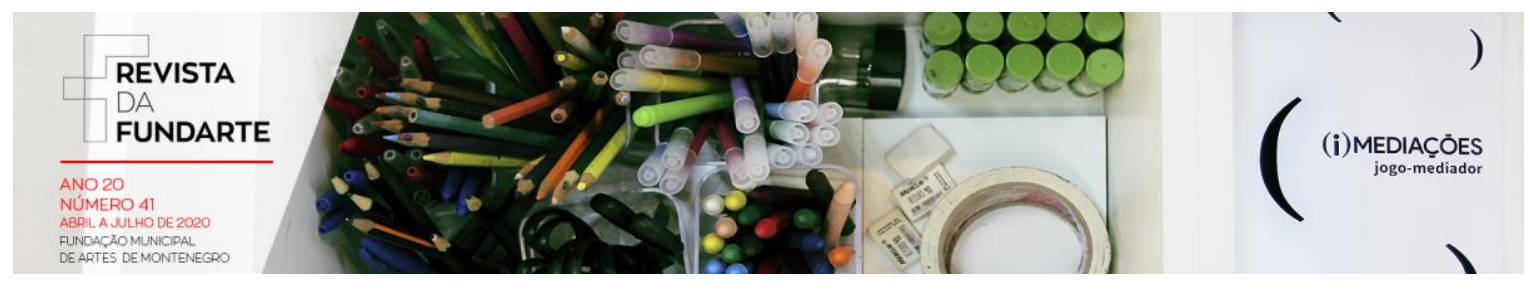

ZAMONER, Maristela. Dança de salão: a caminho da licenciatura. Curitiba: Protexto, 2005.

. Dança de salão: uma análise dos registros de livros na Fundação da Biblioteca Nacional. EFDeportes, Buenos Aires, v.15, n.151, p. 01-01, dez. 2010. Disponível em: $<$ http://www.efdeportes.com/efd151/danca-de-salao-uma-analise-dos-registros-delivros.htm>. Acesso em: 01 jun. 2019.

. Conceitos e definição de Dança de Salão. EFDeportes, Buenos Aires, v.17, n.172, p. 01-01, dez. 2012. Disponível em:

$<$ http://www.efdeportes.com/efd172/conceitos-e-definicao-de-danca-de-salao.htm>. Acesso em: 01 jun. 2019.

NUNES, Bruno Blois; NASCIMENTO, Flávia Marchi. Produção de conhecimento sobre danças de salão: um levantamento de Livros, Teses e Dissertações no Brasil. Revista da FUNDARTE. Montenegro, p.0120, ano 20, no 41, Abril/Junho de 2020.

Disponível em: http://.seer.fundarte.rs.gov.br/index.php/RevistadaFundarte/index> 30 de junho de 2020. 